\title{
Photomorphogenesis of Plants
}

\section{Kathleen A. Nolan, Jia Ci Deng, Victoria Habbchy, and Ameer Rum}

\author{
St. Francis College, Department of Biology, Health Promotion and Health Care Management, \\ 180 Remsen St, Brooklyn NY 11201 USA \\ (knolan@sfc.edu; jiaci281@gmail.com)
}

\begin{abstract}
Students can test the growth of a variety of plants using various wavelengths of light. Norman Lamps sells inexpensive colored LED bulbs that emit the following wavelengths in nm: green (550), purple (443), pink (632), orange (560), amber (572), red (680) and blue (470). We tested growth in height, number of leaves, leaf area (using Image J), fresh weight, and dry weight of lima bean plants grown under purple, amber, blue, and pink lights, compared to controls grown under natural or white light. Initial experiments have revealed that plants grow well when placed under the following lights (6 plants under each wavelength): pink (632 $\mathrm{nm})$, purple (443 nm), blue (470 nm), and amber $(560 \mathrm{~nm})$. Plants grown under purple, amber, and pink lights produced the greatest number of leaves (30) versus 10 for the blue and 20 for the red wavelengths. The control produced 28 leaves. However, even though plants grown in blue and red light produced fewer leaves, all plants produced around the same total leaf surface area, which means that plants grown under the blue and red lights had larger leaves. This indicates a difference in resource allocation for the plants. In the future, we will add stem diameter to our measurements.
\end{abstract}

Keywords: photomorphogenesis, wavelengths, plant growth

Link to Original Poster File: https://doi.org/10.37590/able.v41.poster76

\section{Introduction}

Plants can grow in the dark (seedling germination and roots) and in the light (above ground). Photomorphogenesis is the development of the shape and form of the plant due to the influence of light on photoreceptors in the plant. Much has already been discovered about the complex of genes that control photomorphogenesis, and which wavelengths stimulate which genes. Since 1971, many new plant receptors have been discovered (Briggs and Lin, 2012). For a visual of the complicated network of genes that control plant growth go to:

http://wwwmgs.bionet.nsc.ru/mgs/gnw/genenet/viewer/Ph otomorphogenesis.html.

Smirnova and Stepanenko (2003) used this network and applied filters such as "chloroplasts" or "phytochromes" to highlight specific gene pathways.

Roy et al. (2016) provide review material in their introduction that describes how there is an interaction between photoreceptors such as phytochromes, cryptochromes, phototropins, and hormones and various wavelengths of light that influence the growth of plants. Examples of interaction of gene regulators are given by Fan et al. (2012) and Krzymuski et al. (2014).

In this experiment, students will expose plants to various wavelengths of light to study their photomorphogenesis. They will either sprout fast-growing lima beans or receive sprouts from their instructor. They can choose, or be assigned to use, lights of different wavelengths to which they will expose their seedlings. Students will: observe and measure the growth of their plants at least every three days for three weeks; count the leaves; weigh the plants at the end of the experiment (fresh weight); dry the plants at the end of the experiment and weigh (dry weight); separate the roots from the stem and weigh separately; calculate the root/shoot ratio for both dry and fresh weights; and calculate the area of the leaves using Image J. A high root/shoot ratio indicates that the plant is healthy and is able to garner water and nutrients with an extensive root system. Bantis and Radoglou (2017) conducted a study on the effect of wavelength on forest tree seedlings in a reforestation project and found significant differences in root/shoot ratios under different light conditions. 
Using the literature to guide them, students might think about conducting future experiments such as measuring weight after wilting to see if some plants are more resistant to drought than others. Mao et al. (2005) conducted such an experiment, and also studied the regulation of stomatal openings. Additional experiments, with a wider array of wavelengths, replicates, and types of plants could be attempted, as was by Snowden (2015).

Students can explore the literature to discover what might influence differences in photomorphogenesis. For example, Nelson et al. (2010) found that smoke induced germination of Arabidopsis in the laboratory, and investigated which genes were activated. They hypothesized that plants were able to take advantage of the new source of light available after a fire when the canopy was "opened". Spiro et al. (2004) found that cytokinins influenced photomorphogenesis in C-ferns, by changing the ratios of length versus width of gametophytes. A study by Javanmardi and Emami, (2013) revealed that different wavelengths of light influenced growth in tomato and pepper plants differently. One notable finding was that tomato plants that were grown in blue light had the highest amount of Vitamin C. Another area of investigation would be to examine the many available mutants that exhibit variant forms of photomorphogenesis, such as those described by Song et al. (2009).
Sanchez et al. (2016) note that many molecules that are responsive to light are present in animals as well as plants, such as melatonin, and students can be encouraged to make such connections between these kingdoms of organisms. Students might want to explore the literature to learn the role of specific genes in photomorphogenesis, such as nuclear factor-Y (Myers et al., 2016), or the COP1-SPA complex (Chen et al. 2016). In addition to wavelength, light intensity, as measured in moles of photons, is also important (Nelson and Bugbee 2014). Yang et al. (2016) took a look at how light affects plants ecologically, and found that exposure to red light stimulates growth, whereas exposure to blue light promotes resilience. Goyal et al. (2016) noted that many plants avoid shade in order to have optimal growth. This means that plants may grow differently in crowded versus open conditions. Agricultural studies can also be an avenue for student research projects such as the report by Yuan et al. (2017) that studied lentil growth under various light intensity and wavelengths in order to learn more about this nutritious crop plant. There are many additional examples of practical applications on the study of photomorphogenesis in the literature. 


\section{Student Outline}

\section{Objectives}

Students will:

- Develop and test hypotheses related to plant growth and light wavelength

- Search the literature to find comparable ideas and further experiments that they could conduct

- Measure height, convert to percentage of increase, count leaves, measure wet and dry weight, calculate root/stem ratios, and use Image $\mathrm{J}$ (Fiji) to calculate area of leaves

- Use simple statistics to determine if there are significant differences in growth among plants grown under light bulbs that emit various wavelengths of light

- Make connections between photomorphogenesis and ecology and other branches of science.

\section{Methods and Data Collection}

1. Work out a plan of treatment of your plants. Determine how many plants you want to test (we suggest at least six under each wavelength) and how many plants you will use for each test. We suggest you start with three wavelengths and a control, which will either be natural light or white light.

2. Sprout your lima beans. Sprout at least 50. This should be done in the dark and the lima beans should be placed between wet paper towels. (Your instructor may have done this for you.) A good way to do this is to place wet paper towels on trays or take-out food containers. Place the trays or containers with seeds in drawers or a dark place.

3. Once your lima beans have sprouted, plant them in small pots of soil. Choose the best-looking sprouts to plant.

4. Shine the light bulbs on them and try to shield as much as possible from ambient light. Cardboard shields covered with black paper would work well.

5. Set up a control of six pots that are placed under natural or white light.

6. Water the plants with 100-200 $\mathrm{ml}$ of water (record date and amount of water) every other day or as needed.

7. At the end of the growing period, (three weeks is usually enough time to get the data you need), count the leaves in each plant and record.

8. Measure the height of each plant and record.

9. As the experiment is being conducted, your instructor may want you to measure the plants every day or over a specified time interval.

10. At the end of the experiment, weigh your plants by removing them from the pots, and shaking out any loose dirt from the roots. You may also blot gently with wet paper towels to remove dirt. Weigh on a scale that shows milligrams. This is the fresh weight.Separate the roots from the stems and weigh each separately and record.

11. Take the plants home in zip lock bags that have been labeled by wavelength exposure, take the plants out of the bags and place on a piece of foil or on a pan or cookie sheet, and put them in a $100-200^{\circ} \mathrm{F}$ oven (since most home ovens in the USA are in Fahrenheit). Check them frequently to make sure that they do not scorch or burn. (We have done this at $200^{\circ} \mathrm{F}$ for 20 minutes.) Alternatively, your instructor may dry the plants in a $37^{\circ} \mathrm{C}$ incubator or a drying oven for a few hours to overnight.

12. Bring the plants back into the lab, separate them into roots and shoots, weigh each separately, and write down the root/shoot ratio for each treatment.

13. Make Excel ${ }^{\circledR}$ graphs of your data.

14. Write down any trends you see.

15. If there is time, and your instructor requests this, conduct student t-tests to see if there are any significant differences in height, leaf number, leaf area, difference in weight between fresh and dry, and root/shoot ratios.

Use this website to help you figure out how to do an ANOVA, which would tell you if there was more variation among your groups than within them.

https://www.excel-easy.com/examples/anova.html

If your F-value is above a critical value, than you do have more variation among your treatments than within them and you would reject your null hypothesis that the among group variation and between group variation is the same. If you reject your hypothesis, you can then compare the variation between each pair of data. Use the Bozeman Science video with Mr. Anderson to understand what a student t-test is and how to calculate one. https://www.youtube.com/watch?v=pTmLQvMM-1M

You will need to set up a table to do pair-wise comparisons among all of your treatments (wavelengths).

16. Note which data are significant and what you think it means. 


\section{Materials}

Norman Lamps www.normanlamps.com/sells inexpensive colored LED bulbs that emit the following wavelengths in $\mathrm{nm}$. We used purple (443), pink (632), amber (572), red (680) and blue (470) and white. Other colors such as green and yellow are also available. The example for the purple bulb is:

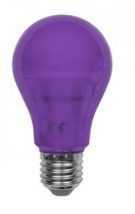

Product Code: LED-A19-5W-PURP UPC: 600300319910

Cost $\$ 3.49$

Availability: Usually ships within 1-2 days

The bulbs range in price from $\$ 1.99$ - \$3.49

\section{Other Supplies}

Lima beans

Paper towels

Containers or zip lock bags for sprouting and storing Ovens (home) or $37^{\circ} \mathrm{C}$ incubators (lab) or drying oven

Soil

Pots ( 8 oz. would be fine)

Cardboard covered with black paper to shield the plants Beakers $(250 \mathrm{ml})$ to accurately measure water

\section{Notes for the Instructor}

Plants grown under purple, pink and amber lights tied for the highest overall number of leaves after three weeks, with the control close behind. Plants grown under red and blue lights produced the fewest leaves. The plants grown under purple wavelengths grew the tallest (averaging $45 \mathrm{~cm}$ in height; followed by amber at $38 \mathrm{~cm}$. Blue tied with the control at $30 \mathrm{~cm}$. The pink-grown, $25 \mathrm{~cm}$ and the shortest was red at $20 \mathrm{~cm}$. When the final data after the three weeks are put together, some interesting trends result. Even though plants grown under the red and blue lights had less leaves, than the other plants, their leaves were larger, as we can see by the leaf areas. This corresponds with the significance of red and blue wavelengths as the primary wavelengths in photosynthesis. There was more variation among leaf numbers than there was in leaf area. Also, the blue light plants grew relatively tall despite having the lowest number of leaves. Selected data is presented in the Appendix. This project could be conducted in two ways:

a. As a curriculum-embedded undergraduate research experience (CURE) for the entire class (each within-class group could be given three (or more) lamps with light bulbs of varying wavelengths)

or

b. As a group lab project for one small group of three-four students.

You can either:

a. sprout lima beans ahead of time or

b. have students sprout the lima beans or

c. have students plant the lima beans directly.

We preferred option (b) so that students see the actual roots and stems as they start growing.

\section{Cited References}

Bantis F, Radoglou K. 2017. Morphology, development, and transplant potential of Prunus avium and Cornus sanguinea seedlings growing under different LED lights. Turkish Journal of Biology, 41(2), 314-321.

Briggs W, Lin CT. 2012. Photomorphogenesis-from one photoreceptor to 14: 40 years of progress. 2012. Molecular Plant (Oxford University Press / USA). 5(3):531-532.

Chen S, Wirthmueller L, Stauber J, Lory N, Xu Holtkotte X, Leson L, ... Hoecker U. 2016. The functional divergence between SPA1 and SPA2 in Arabidopsis photomorphogenesis maps primarily to the respective $\mathrm{N}$-terminal kinase-like domain. BMC Plant Biology. 16:1-12.

Fan XY, Sun Y, Cao DM, Bai MY, Luo XM, Yang HJ, ... Wang ZY. 2012. BZS1, a B-box protein, promotes photomorphogenesis downstream of both brassinosteroid and light signaling pathways. Molecular Plant (Oxford University Press / USA). 5(3):65-74.

Goyal A, Karayekov E, Galvão VC, Ren H, Casal JJ, Fankhauser C. 2016. Shade Promotes Phototropism through Phytochrome BControlled Auxin Production. Curr Biol. 26(24):3280-3287. doi: 10.1016/j.cub.2016.10.001. Epub 2016 Nov 23.

https://www.excel-easy.com/examples/anova.html

http://wwwmgs.bionet.nsc.ru/mgs/gnw/genenet/viewer/Ph otomorphogenesis.html 
https://www.youtube.com/watch?v=pTmLQvMM-1M

Javanmardi J, Emami S. 2013. Response of Tomato and Pepper Transplants to Light Spectra Provided by Light Emitting Diodes. International Journal of Vegetable Science. 19(2):138-149.

Krzymuski M, Cerdán PD, Zhu L, Vinh A, Chory J, Huq E, Casal J J. 2014. Phytochrome A antagonizes phytochrome interacting factor 1 to prevent overactivation of photomorphogenesis. Molecular Plant (Oxford University Press / USA). 7(9):1415-1428.

Mao J, Zhang YC, Sang Y, Li QH, Yang HQ. 2005. A role for Arabidopsis cryptochromes and COP1 in the regulation of stomatal opening. PNAS. 102(34):12270-12275.

Myers ZA, Kumimoto RW, Siriwardana CL, Gayler KK, Risinger JR, Pezzetta D, Holt III BF. 2016. Nuclear factor Y, Subunit C (NF-YC) transcription factors are positive regulators of photomorphogenesis in Arabidopsis thaliana. PLoS Genetics. 12(9):1-30.

Nelson DC, Flematti GR, Riseborough JA., Ghisalberti EL, Dixon KW, Smith SM. 2010. Karrikins enhance light responses during germination and seedling development in Arabidopsis thaliana. PNAS. 107(15):7095-7100.

Nelson JA, Bugbee B. 2014. Economic analysis of greenhouse lighting: light emitting diodes vs. high intensity discharge fixtures. PLoS ONE. 9(6): $1-10$.

Roy A, Sahoo D, Tripathy B. 2016. Light-hormone interaction in the red-light-induced suppression of photomorphogenesis in rice seedlings. Protoplasma. 253(2):393-402.

Sanchez BEJ, Mediavilla MD, Vriend,J, Reiter RJ. 2016. Constitutive photomorphogenesis protein 1 ( COP1) and COP9 signalosome, evolutionarily conserved photomorphogenic proteins as possible targets of melatonin. Journal of Pineal Research. 61(1):41-51.

Smirnova OG, Stepanenko IL. 2003. Application of filter technology in photomorphogenesis gene network. In Silico Biology. 3(1/2): 117.

Snowden MC. 2015. Effects of blue and green light on plant growth and development at low and high photosynthetic photon flux. All Graduate Theses and Dissertations. 4613.

https://digitalcommons.usu.edu/etd/4613

Song L, Zhou XY, Li L, Xue LJ, Yang X, Hong-Wei Xue HW. 2009. Genome-wide analysis revealed the complex regulatory network of brassinosteroid effects in photomorphogenesis. Molecular Plant (Oxford University Press / USA). 2(4):755-772.

Spiro MD, Torabi B, Cornell CN. 2004. Cytokinins induce photomorphogenic development in darkgrown gametophytes of Ceratopteris richardii. Plant \& Cell Physiology. 45(9):12521260.

Yang D, Seaton DD, Krahmer J, Halliday KJ. 2016. Photoreceptor effects on plant biomass, resource allocation, and metabolic state.

PNAS. 113 (27):7667-7672.

Yuan HY, Shyamali S, Vandenberg A, BettKE. 2017. Flowering and growth responses of cultivated lentil and wild lens germplasm toward the differences in red to far-red ratio and photosynthetically active radiation. Frontiers in Plant Science 8:386. https://doi.org/10.3389/fpls.2017.00386

\section{Acknowledgments}

Thank you very much to Leah Kovenat, Allen Burdowski, Marlon Joseph, Noemi Rivera, StacyAnn Gooden, Kristen Casares and Michelle Batchu..

\section{About the Authors}

Kathleen A. Nolan, Ph.D. received a B.S. in Biology with a minor in Geology from Northeastern University in 1979, an M.A. in Biology from the City College of New York in 1983, and a Ph.D. in Biology from the City University of New York in 1992. Her dissertation was titled, "Mitochondrial DNA analysis of American shad (Alosa sapidissima) populations. She is a Professor of Biology and has been the Chair of the Biology, Health Promotion, and Health Care Management at St. Francis College since 2006. She loves teaching and developing new labs.

Jia-Ci Deng, Victoria Habbchy, and Ameer Rum are undergratudate students. 


\section{Appendix: Selected Data}

Table 1. Height of plants $(\mathrm{cm})$ grown under various wavelengths.

\begin{tabular}{|l|l|l|l|l|l|l|}
\hline \multicolumn{7}{|c|}{ Wavelength } \\
\hline Weeks & Pink & Red & Blue & Control & Purple & Amber \\
\hline 1 & 5.75 & 10.1 & 16 & 9.625 & 10.5 & 6.625 \\
\hline 2 & 18.325 & 20.325 & 29.95 & 19.7 & 33.37 & 19.325 \\
\hline 3 & 25.125 & 23 & 30.25 & 29.75 & 43.875 & 36.5 \\
\hline
\end{tabular}

Average Plant Height(cm)

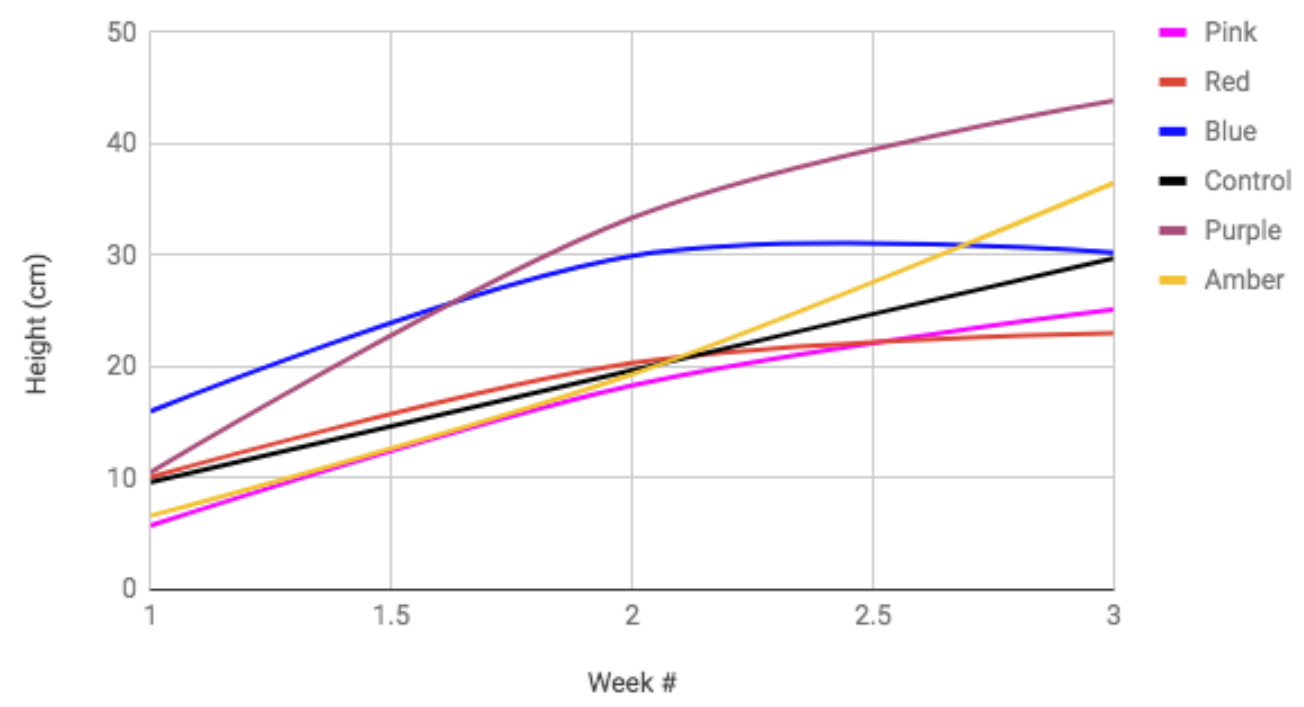

Figure 1. Height of plants grown under various wavelengths.

Table 2. Total leaf area $\left(\mathrm{cm}^{2}\right)$ of plants grown under various wavelengths.

\begin{tabular}{|c|c|c|}
\hline Wavelength & Week 2 & Week 3 \\
\hline Pink & 14.93 & 31.6 \\
\hline Red & 8.75 & 27.02 \\
\hline Blue & 8.29 & 26.07 \\
\hline Control & 13.73 & 29.97 \\
\hline Purple & 8.46 & 34.31 \\
\hline Amber & 14.97 & 26.74 \\
\hline
\end{tabular}




\section{Average Leaf Area}
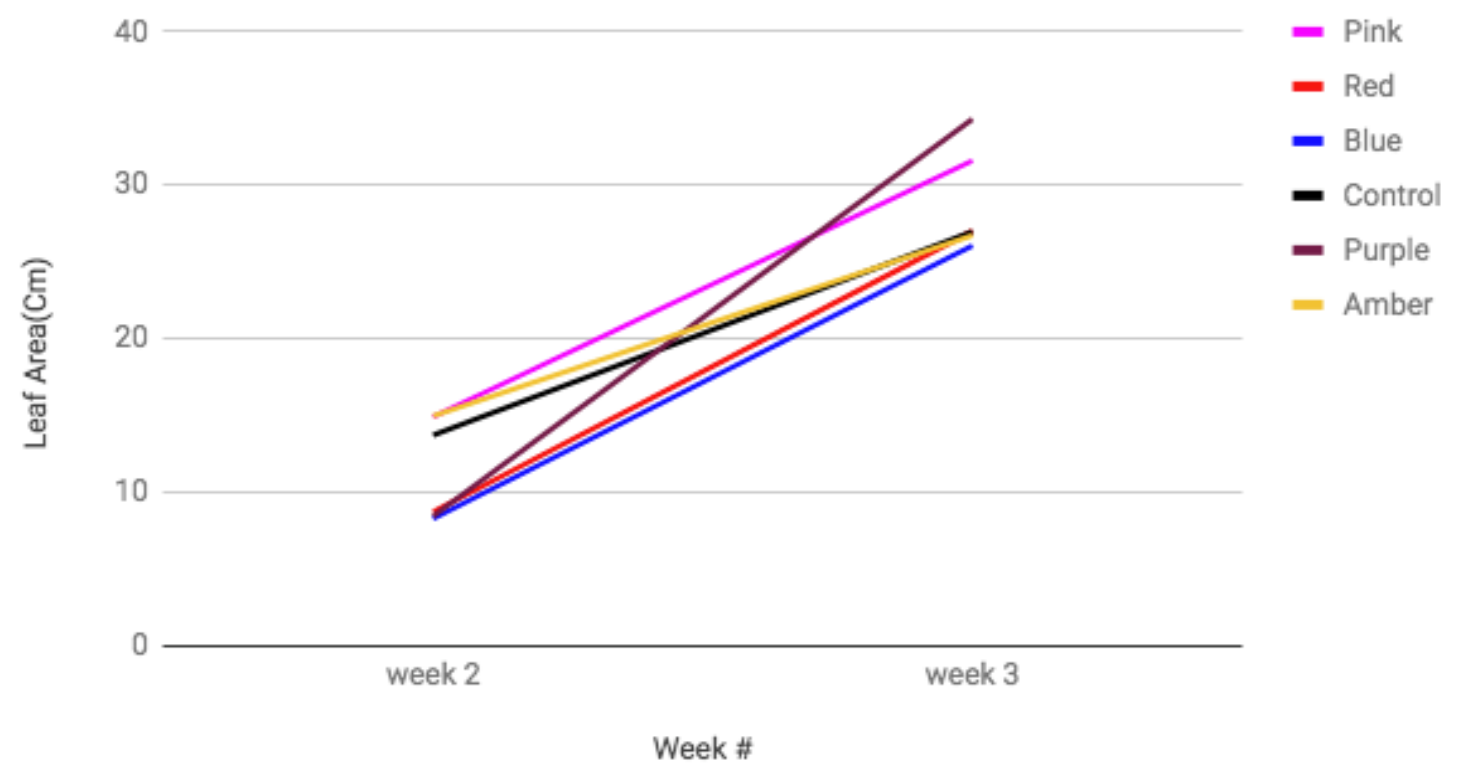

Figure 2. Area of plants grown under various wavelengths.

Table 3. Comparisons of photomorphogenesis parameters.

\begin{tabular}{|c|c|c|}
\hline & leaf area $\left(\mathrm{cm}^{2}\right)$ & Height $(\mathrm{cm})$ \\
\hline pink & 31.6 & 25.125 \\
\hline red & 27.02 & 23 \\
\hline blue & 26.07 & 30.25 \\
\hline control & 29.97 & 29.75 \\
\hline purple & 34.31 & 43.878 \\
\hline amber & 26.74 & 36.5 \\
\hline
\end{tabular}

Table 4. Comparisons of fresh and dry weights of plants.

\begin{tabular}{|c|c|c|c|c|}
\hline Wavelength & $\begin{array}{c}\text { Fresh } \\
\text { weight } \\
(\mathrm{g})\end{array}$ & $\begin{array}{c}\text { Dry } \\
\text { weight } \\
(\mathrm{g})\end{array}$ & $\begin{array}{c}\text { Difference } \\
(\mathrm{g})\end{array}$ & $\begin{array}{c}\% \mathrm{FW} \\
\text { of } \\
\text { WW }\end{array}$ \\
\hline Purple & 11.8 & 2.2 & 9.6 & 18.6 \\
\hline Blue & 7.8 & 2 & 5.8 & 25.6 \\
\hline Red & 7.5 & 1.4 & 6.1 & 18.7 \\
\hline Control & 8.5 & 1 & 7.5 & 11.8 \\
\hline Pink & 10.2 & 1.4 & 8.8 & 13.7 \\
\hline Amber & 11.8 & 3 & 8.8 & 25.4 \\
\hline
\end{tabular}




\section{Fresh mass and Dry Mass}

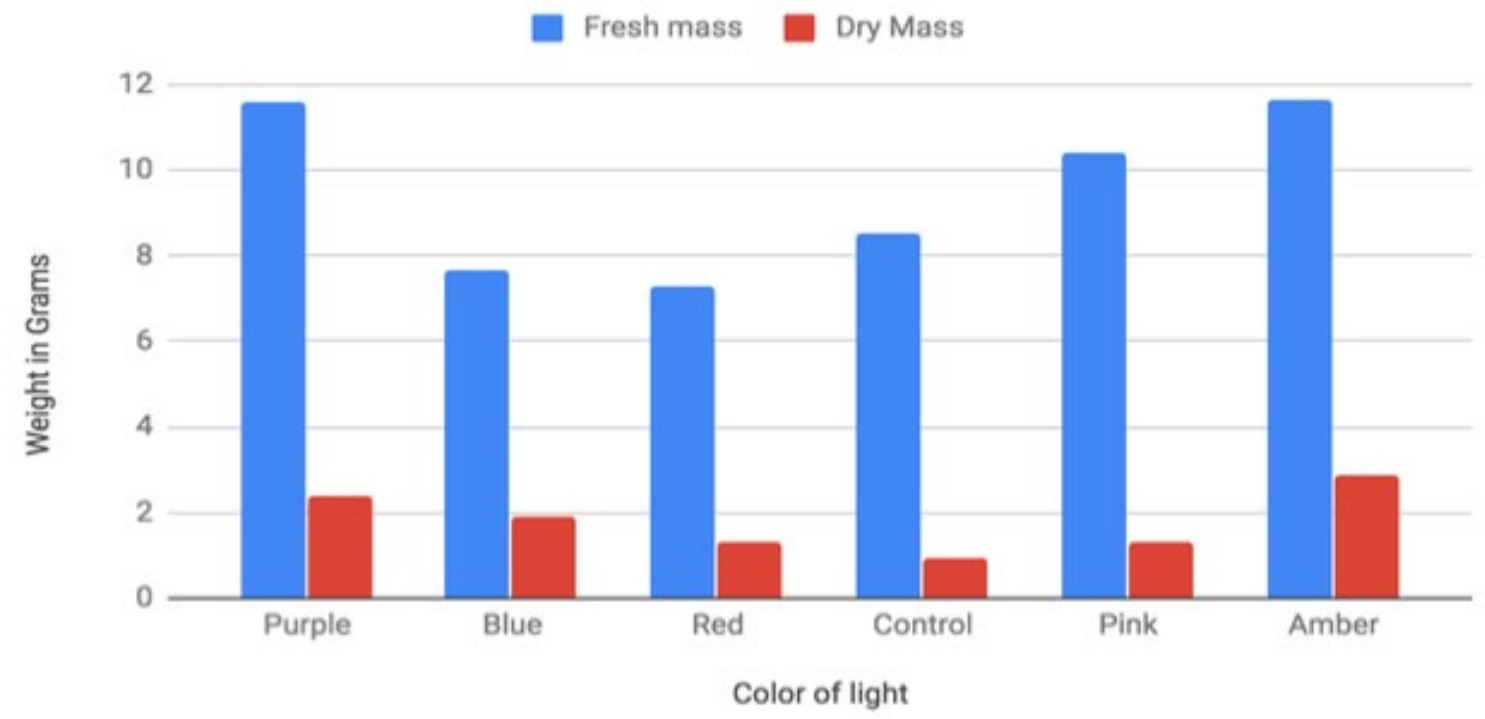

Figure 3. Comparisons of fresh and dry weights of plants. 


\section{Mission, Review Process \& Disclaimer}

The Association for Biology Laboratory Education (ABLE) was founded in 1979 to promote information exchange among university and college educators actively concerned with teaching biology in a laboratory setting. The focus of ABLE is to improve the undergraduate biology laboratory experience by promoting the development and dissemination of interesting, innovative, and reliable laboratory exercises. For more information about ABLE, please visit http://www.ableweb.org/.

Advances in Biology Laboratory Education is the peer-reviewed publication of the conference of the Association for Biology Laboratory Education. Published articles and extended abstracts are evaluated and selected by a committee prior to presentation at the conference, peer-reviewed by participants at the conference, and edited by members of the ABLE Editorial Board. Published abstracts are evaluated and selected by a committee prior to presentation at the conference.

\section{Citing This Article}

Nolan KA, Deng JC, Habbchy V, Rum A. 2020. Photomorphogenesis of plants. Article 76 In: McMahon K, editor. Advances in biology laboratory education. Volume 41. Publication of the 41st Conference of the Association for Biology Laboratory Education (ABLE). http://www.ableweb.org/volumes/vol-41/?art=\#

Compilation (C) 2020 by the Association for Biology Laboratory Education, ISBN 1-890444-17-0. All rights reserved. No part of this publication may be reproduced, stored in a retrieval system, or transmitted, in any form or by any means, electronic, mechanical, photocopying, recording, or otherwise, without the prior written permission of the copyright owner.

ABLE strongly encourages individuals to use the exercises in this volume in their teaching program. If this exercise is used solely at one's own institution with no intent for profit, it is excluded from the preceding copyright restriction, unless otherwise noted on the copyright notice of the individual chapter in this volume. Proper credit to this publication must be included in your laboratory outline for each use; a sample citation is given above. 